\title{
Miscibility and Crystallization Behavior of Poly(butylene succinate) and Poly(vinylidene fluoride) Blends
}

\author{
Jeong-Chang Lee, Hare Tazawa, Takayuki Ikehara, \\ and Toshio NisHI \\ Department of Applied Physics, School of Engineering, The University of Tokyo, \\ Bunkyo-ku, Tokyo 113-8656, Japan
}

(Received September 25, 1997)

\begin{abstract}
Miscibility and crystallization behavior of biodegradable poly(butylene succinate) (PBSU) and poly(vinylidene fluoride) (PVDF) blends, where two components are crystallizable have been investigated by differential scanning calorimerty and optical microscopy. From cloud point observation of the blends they are found to have lower critical solution temperature behavior. Spherulites of PVDF grew linearly with crystallization time and the growth rate decreased with increase in PBSU content. The interaction parameter $\chi_{12}$, obtained from melting point depression of PVDF gave the value of -0.139 . However, the crystallization and melting behavior of low- $T_{\mathrm{m}}$ component PBSU were quite different from that of high- $T_{\mathrm{m}}$ component PVDF: (i) the magnitude of the melting point depression of PBSU was changed strongly with cooling rate, (ii) for a given $T_{\mathrm{c}}$, the melting point of PBSU increased with increase in PVDF content, in contrast to the decrease of the melting point in usual amorphous/crystalline blends, (iii) the spherulitic growth rate $G$ of PBSU decreased very slightly with increase in PVDF content at a given $T_{\mathrm{c}}$ and the morphology of the PBSU were strongly dependent upon the crystallization condition. Microscopic observations and Avrami analysis of the crystallization of PBSU in the blends lead to the conclusion that all these unique crystallization behaviors of PBSU presented in this article are ascribed to the presence of PVDF crystals at the temperature where the crystallization of PBSU occurs.
\end{abstract}

KEY WORDS Poly(butylene succinate) / Poly(vinylidene fluoride) / Polymer Blend / Melting Point Depression / Crystallization / Biodegradable Polyester /

Miscibility between two amorphous polymers have been studied intensively. Miscibility and crystallization behaviors of amorphous/crystalline polymers have also been examined, and a number of miscible blends are known, e.g., poly(vinylidene fluoride) (PVDF)/poly (methyl methacrylate) (PMMA), ${ }^{1}$ poly( $\varepsilon$-caprolactone) (PCL)/poly(vinyl chloride) (PVC), ${ }^{2-4}$ copolyester/polycarbonate, ${ }^{5}$ PCL/poly(4-hydroxystyrene), ${ }^{6}$ poly(3-hydroxybutyrate) (PHB)/poly(epichlorohydrin), ${ }^{7} \mathrm{PHB} /$ poly(vinyl acetate), ${ }^{8}$ and $\mathrm{PHB} /$ poly(vinylidene chlorideco-acrylonitrile). ${ }^{9}$ On the other hand, blends in which both components are crystalline polymers have received much less attention than amorphous/amorphous or amorphous/crystalline systems. There are very few studies on the miscibility and crystallization behavior of polymer blends between two crystalline polymers, except for a recent series of papers by Manley et al. ${ }^{10-12}$ Miscible crystalline/crystalline blend is a rare phenomenon and only a few pairs have been reported to form miscible system. This is because the crystalline polymer pairs having attractive interactions between the two components are very rare. Although such binary blends of crystallizable polymers are very rare, these blends can be divided into three main categories. These are (i) polymer/low molecular weight diluents, such as PCL/ Trioxane mixture ${ }^{13}$; (ii) blends of chemically similar species, such as blends of two poly(aryl ether ketones), ${ }^{14}$ blends of two polyethylenes, ${ }^{15,42-44}$ homopolymer/segmented block copolymer, ${ }^{16,17}$ copolymers of vinylidene fluoride/trifluoroethylene, ${ }^{18}$ vinylidene fluoride-co-tetrafluoroethylene/vinylidene fluoride-co-hexafluoroacetone $^{19}$; (iii) two polymers of chemically different structures, such as $\mathrm{PCL} /$ poly(vinylidene chloride), ${ }^{20,21}$ $\mathrm{PHB} /$ poly(ethylene oxide) (PEO), ${ }^{22}$ and poly(butylene adipate) (PBA)/PVDF. ${ }^{10-12}$ The blends in category (ii) form cocrystals in a certain crystallization conditions, however, the blends in category (iii) form segregated crystals. For the blends shown in category (iii), however, the melting point of the two components have been $c a$. $100^{\circ} \mathrm{C}$ apart. Then, the crystallization of the low- $T_{\mathrm{m}}$ component was seriously influenced by the presence of the high- $T_{\mathrm{m}}$ component. When the high- $T_{\mathrm{m}}$ component is crystallized, the low- $T_{\mathrm{m}}$ component is remained in amorphous state and the crystallization behavior of the high- $T_{\mathrm{m}}$ component is not changed as observed in crystalline/amorphous polymer blends.

On the other hand, when the low- $T_{\mathrm{m}}$ component is crystallized, the high- $T_{\mathrm{m}}$ component has been already crystallized and the low- $T_{\mathrm{m}}$ component should crystallize in the solid matrix of the high- $T_{\mathrm{m}}$ component. In this sense, the crystallization of the low- $T_{\mathrm{m}}$ component is unique in the blends where two polymers are crystalline. It is expected that, in crystalline/crystalline polymer blends, the crystallization behavior of the one component affects the crystallization behavior of the other. The crystallization behavior of crystalline component in the crystalline/crystalline polymer blends should be quite different from that of the crystalline component in the amorphous/crystalline blends.

In this study, we have chosen the mixture of poly(butylene succinate) (PBSU)/PVDF as a model crystalline/crystalline polymer system. We chose this crystalline polymer pair because the blends have less difference in $T_{\mathrm{m}}\left(\mathrm{ca} .45^{\circ} \mathrm{C}\right)$ than that of the blends in the category (iii), the nucleation frequency of PBSU is very low (this leads to a formation of very large spherulites) and the spherulitic growth rate of PBSU is faster than that of PVDF (therefore, PBSU can crystallize competitively with PVDF). Additionally, PBSU has carbonyl groups which are supposed to cause dipole-dipole interaction 
Table I. Molecular characteristics, sources, and codes of the polymers

\begin{tabular}{|c|c|c|c|c|}
\hline Polymer & Code & Source & $M_{w}$ & $T_{\mathrm{m}}^{\mathrm{a}} /{ }^{\circ} \mathrm{C}$ \\
\hline Poly(butylene succinate) & PBSU & Tounen Chem. & 54000 & 115 \\
\hline Poly(vinylidene fluoride) & PVDF $^{b}$ & Pennwalt & 572000 & 158 \\
\hline Poly(vinylidene fluoride) & PVDF $(140 \mathrm{~K})^{\mathrm{c}}$ & Polysciences & 140000 & 165 \\
\hline
\end{tabular}

${ }^{a}$ Determined by DSC at a heating rate of $10^{\circ} \mathrm{Cmin}^{-1} \cdot{ }^{b}$ Used for phase diagram, crystallization and melting behavior. ${ }^{c}$ Used for the observation of spherulitic morphologies.

with PVDF.

In this article, miscibility and crystallization behavior of PBSU/PVDF blends were investigated by differential scanning calorimetry (DSC) and optical microscopy. Specifically, crystallization and melting behavior of the low- $T_{\mathrm{m}}$ component (PBSU) were analyzed under various crystallization conditions. It turned out that the PBSU/ PVDF blend is thermodynamically miscible because of the lower critical solution temperature behavior (LCST) of the blends and the depression of the equilibrium melting temperature of high- $T_{\mathrm{m}}$ component (PVDF) with increasing low- $T_{\mathrm{m}}$ component (PBSU). However, the crystallization behavior of PBSU was influenced strongly by the presence of PVDF crystals, which result in the drastic morphology changes in PBSU. To our knowledge, this article is the first one that the crystallization behavior and the spherulitic morphology of low- $T_{\mathrm{m}}$ component in crystalline/crystalline polymer blend was investigated intensively.

\section{EXPERIMENTAL}

\section{Materials and Sample Preparation}

A list of the polymers used in this study is shown in Table I. PBSU is a biodegradable polyester. The PBSU/ PVDF blends were prepared with a mutual solvent $N, N$ dimethylformamide (DMF) at an elevated temperature. After the solvent was removed at room temperature, the samples were kept in a vacuum at $20^{\circ} \mathrm{C}$ for a week.

\section{Microscopic Observation}

To study the morphology of the blends and the spherulitic growth rate of the PBSU and PVDF spherulites, samples cast on cover-glasses were observed under a polarizing microscope (OLYMPUS BHA-P) equipped with a temperature controller (LINKAM TH-600). The samples were heated to $190^{\circ} \mathrm{C}$ for $5 \mathrm{~min}$ and then rapidly cooled to the crystallization temperature $T_{\mathrm{c}}$. The diameter of the growing spherulites was measured as a function of time by taking photographs during crystallization. To observe the phase separation behavior the samples were heated at the rate of $20^{\circ} \mathrm{Cmin}^{-1}$ to about $20^{\circ} \mathrm{C}$ below the phase separation temperature of the blends. After holding at this temperature for $5 \mathrm{~min}$ to insure even temperature distribution in the sample, temperature controller was quickly brought up to the desired temperature and maintained there while the phase change was observed with an optical microscope.

\section{Differential Scanning Calorimetry (DSC)}

The melting point $T_{\mathrm{m}}$ of the samples was determined by TA Instruments DSC 2910 with a Thermal Analyst 2000. The melting temperature $T_{\mathrm{m}}$ of the solution-cast samples was obtained by heating the sample to $190^{\circ} \mathrm{C}$ at $20^{\circ} \mathrm{Cmin}^{-1}$. The value of $T_{\mathrm{m}}$ was taken as the peak temperature of the DSC melt peak.

To investigate the effect of the high- $T_{\mathrm{m}}$ component on the crystallization behavior of the low- $T_{\mathrm{m}}$ component, we crystallized the PBSU/PVDF blends under various crystallization conditions and measured the melting points of the two components. The thermal programs used for crystallization of the blends are shown in Figure 1. Program (a) was used for the effect of slow crystallization conditions. The samples were maintained at $190^{\circ} \mathrm{C}$ for $5 \mathrm{~min}$ to ensure complete melting of the two PBSU and PVDF crystals before being cooled at $10^{\circ} \mathrm{C} \mathrm{min}^{-1}$ or $1^{\circ} \mathrm{C} \mathrm{min}^{-1}$ to room temperature. During this cooling process, crystallization of the two components occurred, however, the cooling rate was slow, all the PVDF component crystallized before the PBSU started to crystallize. After the samples were cooled to room temperature, blends were heated to $190^{\circ} \mathrm{C}$ at a heating rate of $20^{\circ} \mathrm{C} \mathrm{min}^{-1}$ for the observation of their melting behavior. Program (b), with a cooling rate of $100^{\circ} \mathrm{C} \mathrm{min}^{-1}$, was used for the effect of fast crystallization conditions. In this fast cooling condition, some PBSU could crystallize simultaneously with PVDF because the PVDF has less time to crystallize. Program (c) was used to study the cold crystallization of the blends. The samples were quenched in a liquid nitrogen after maintaining at $190^{\circ} \mathrm{C}$ for $5 \mathrm{~min}$. After the quenching was completed, the samples were moved to DSC cell maintained at $-80^{\circ} \mathrm{C}$ and heated at a heating rate of $20^{\circ} \mathrm{C}$ $\mathrm{min}^{-1}$. During this heating process, crystallization and melting behavior were observed. Program (d) was intended for investigating the effect of the presence of PVDF crystals on the crystallization behavior of PBSU. The samples were cooled to $150^{\circ} \mathrm{C}$ after maintaining at $190^{\circ} \mathrm{C}$ for $5 \mathrm{~min}$ and, at this temperature, the PVDF melt was allowed to crystallize isothermally. After the crystallization of PVDF was completed, the samples were further cooled to $90^{\circ} \mathrm{C}$ to crystallize the PBSU in the matrix of the PVDF crystals. The melting behavior of isothermally crystallized blends was also analyzed by DSC. The samples were melted at $190^{\circ} \mathrm{C}$ for $5 \mathrm{~min}$, then rapidly cooled to the desired crystallization temperature $T_{\mathrm{c}}$. After crystallization they were heated above the melting point at a scanning rate of $20^{\circ} \mathrm{C} \mathrm{min}^{-1}$.

\section{RESULTS}

\section{Phase Diagram}

Figure 2 shows the phase diagram of the PBSU/PVDF blends. Since the glass transition temperature $T_{\mathrm{g}}$ ( $c a$. $-37^{\circ} \mathrm{C}$ for PBSU and $c a .-40^{\circ} \mathrm{C}$ for PVDF) of the two constituent polymers are so close that it was unsuccessful 


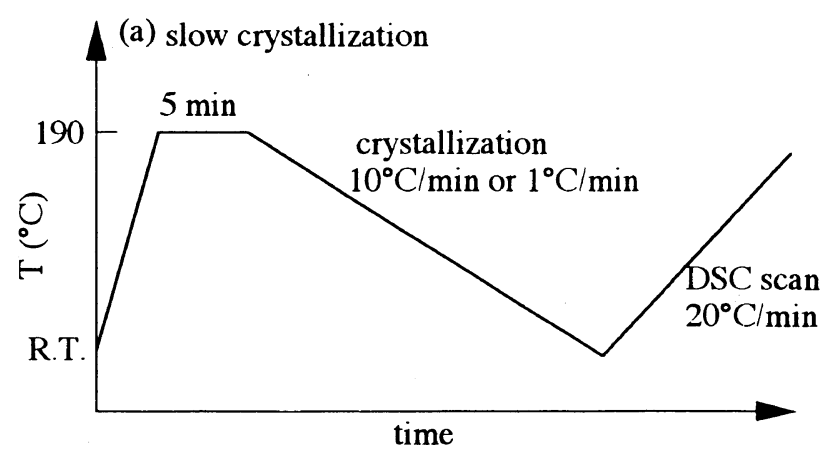

(b) fast crystallization
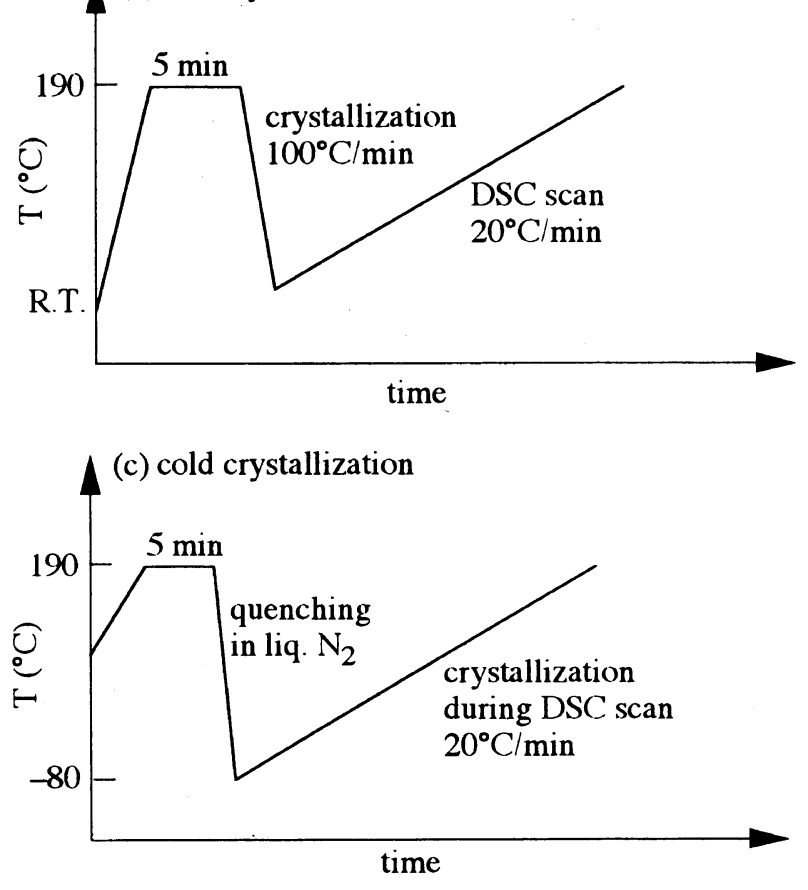

(d) two-step crystallization

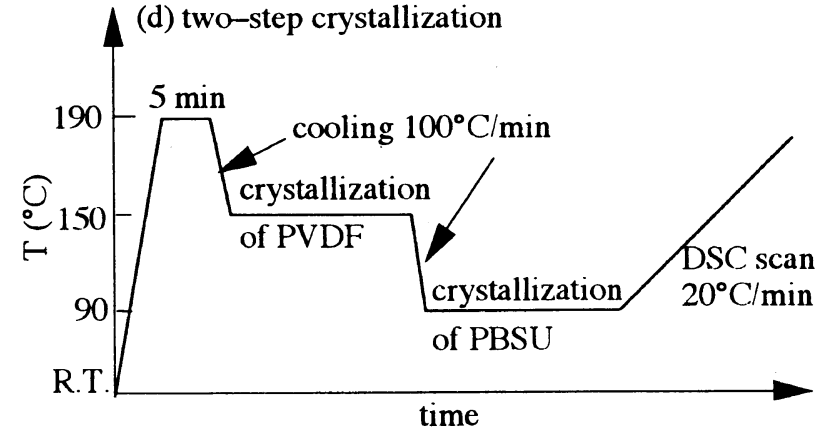

Figure 1. Thermal programs used for DSC measurements and optical microscopic observations.

to verify the miscibility of the blends with $T_{\mathrm{g}}$. However, cloud point observation of the blends showed lower critical solution temperature (LCST) behavior. Therefore the PBSU/PVDF blends form thermodynamically miscible mixture above the melting point of PVDF (upto $200^{\circ} \mathrm{C}$ ). The cloud point curve is asymmetric and skewed to the PBSU rich side because of the difference in molecular weight between the two polymers. Since PBSU/PVDF blends have dissimilar chemical structure, the two crystalline components formed segregated crystals over the whole composition range as shown in

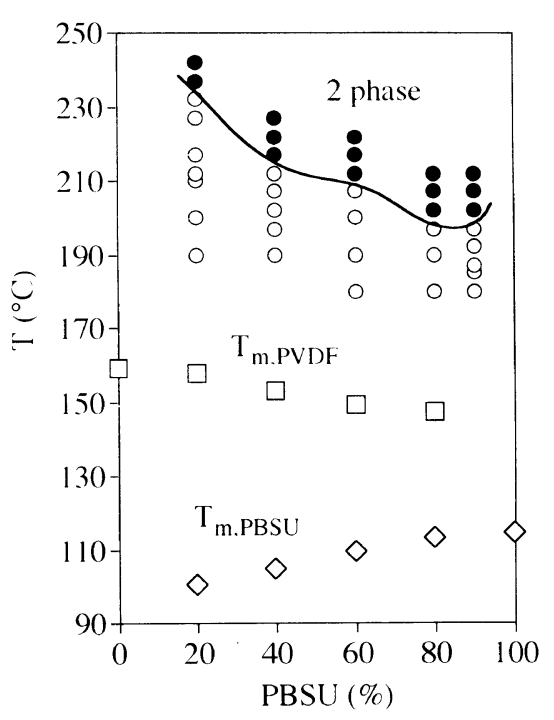

Figure 2. Phase diagram of PBSU/PVDF blends. The blends show LCST phase behavior. The melting points of the blends were measured after quenching into liquid nitrogen from $190^{\circ} \mathrm{C}$. $\bigcirc$, represent blends that remained as a single phase; $\boldsymbol{O}$, indicate phase separation.

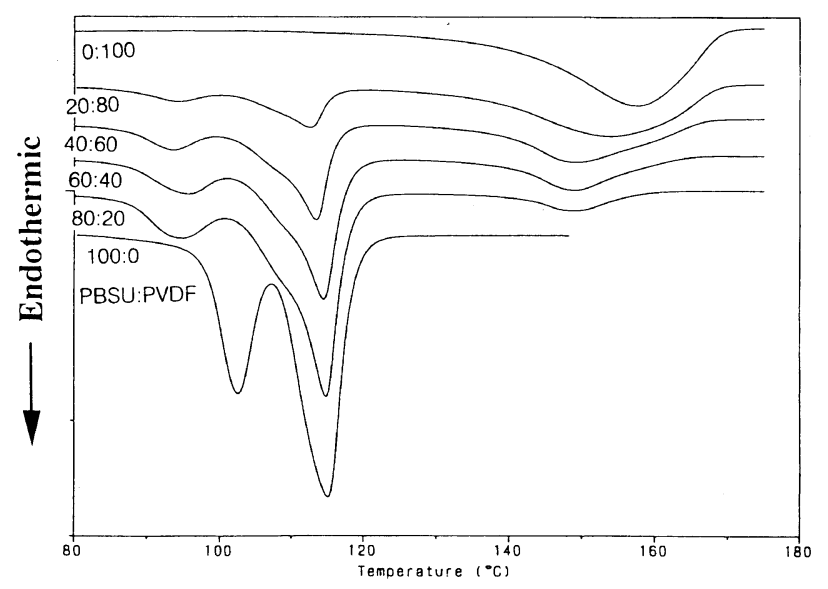

Figure 3. DSC melting endotherms of solution-cast PBSU/PVDF blends. Each crystalline component formed segregated crystals. Scan rate was $20^{\circ} \mathrm{Cmin}^{-1}$.

Figure 2. Before the measurement of melting point, the samples were quenched into liquid nitrogen from the melt after being held at $190^{\circ} \mathrm{C}$ for $5 \mathrm{~min}$. The $T_{\mathrm{m}}$ for each component decreased with increasing the fraction of the other component and the degree of the melting point depression was dependent upon crystallization conditions. In the temperature range between $T_{\mathrm{m}}(\mathrm{PBSU})$ and $T_{\mathrm{m}}$ (PVDF), the blends have two amorphous components and a crystalline component (i.e., amorphous PBSU, uncrystallized PVDF and crystallized PVDF crystals). It is expected that the crystallization behavior of PBSU is profoundly influenced by the PVDF crystals. These facts will be discussed in the next section.

\section{Crystallization and Melting Behavior}

Figure 3 shows the DSC melting curves of solution-cast PBSU/PVDF blends. All the blends containing PBSU showed two melting peaks. This double melting behavior is frequently found in miscible blends containing microbial polyesters, such as PHB prepared by casting from solvent. ${ }^{23,24}$ However, the blends crystallized from 
Table II. The melting point $T_{m}$ and the enthalpy of fusion $\Delta H_{\mathrm{m}}$ of solution-cast PBSU/PVDF blends

\begin{tabular}{|c|c|c|c|c|}
\hline \multirow{2}{*}{ PBSU/PVDF } & $T_{\mathrm{m}, \mathrm{PBSU}}$ & $\Delta H_{\mathrm{PBSU}}$ & $T_{\mathrm{m}, \mathrm{PVDF}}$ & $\Delta H_{\mathrm{m}, \mathrm{PVDF}}$ \\
\hline & ${ }^{\circ} \mathrm{C}$ & $\mathrm{Jg}^{-1}$ & ${ }^{\circ} \mathrm{C}$ & $\mathrm{Jg}^{-1}$ \\
\hline $100: 0$ & 114.9 & 149.7 & - & - \\
\hline $80: 20$ & 114.7 & 108.8 & 149.1 & 10.75 \\
\hline $60: 40$ & 114.4 & 76.8 & 149.0 & 23.9 \\
\hline $40: 60$ & 113.2 & 49.8 & 149.1 & 37.7 \\
\hline $20: 80$ & 112.4 & 22.4 & 153.8 & 57.5 \\
\hline $0: 100$ & - & - & 157.4 & 83.2 \\
\hline
\end{tabular}

(a)

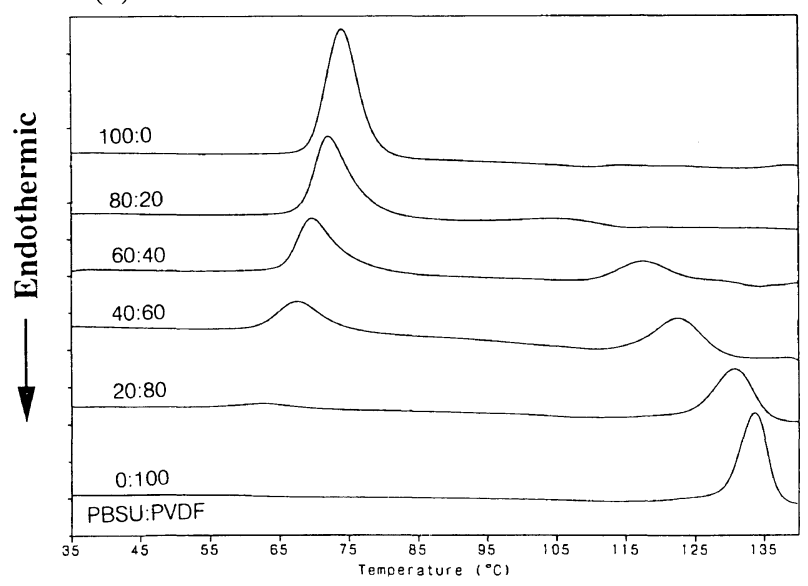

(b)

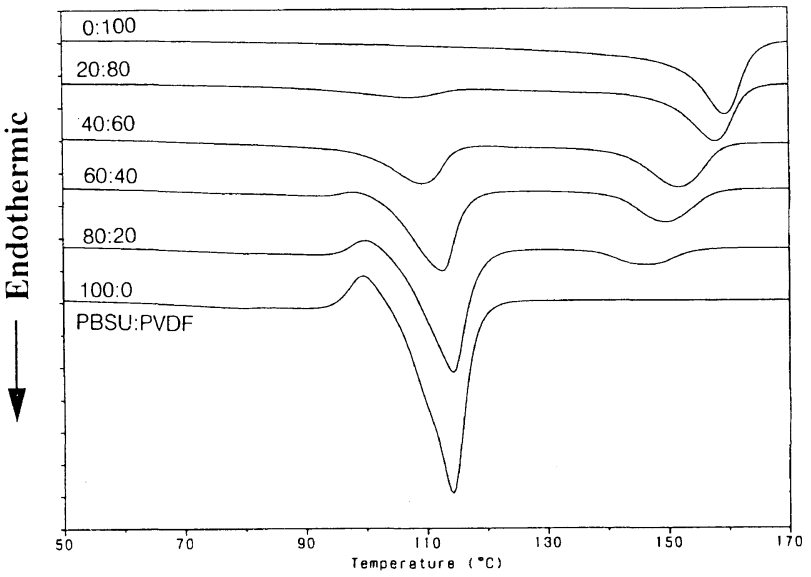

Figure 4. DSC scans showing (a) the crystallization of PBSU/PVDF blends on cooling $10^{\circ} \mathrm{Cmin}^{-1}$, (b) the melting endotherms of the samples crystallized on cooling $10^{\circ} \mathrm{C} \mathrm{min}^{-1}$. Scan rate was $20^{\circ} \mathrm{C} \mathrm{min} \mathrm{min}^{-1}$. Each crystalline component formed segregated crystals. The higher and the lower crystallization/melting peaks are attributed to the crystallization/melting of PVDF and PBSU phases, respectively.

the melt showed only a single peak that corresponds to the higher temperature peak (see Figure 4(b)). Therefore, we report the higher melting peak of PBSU here.

Table II shows how the $T_{\mathrm{m}}$ and the value of enthalpy of fusion $\Delta H_{\mathrm{m}}$ for each component depends upon the weight fraction of the other component. The $T_{\mathrm{m}}$ for each component decreased with increasing the fraction of the other component, however, the melting point depression of low- $T_{\mathrm{m}}$ component (PBSU) was smaller than that of high- $T_{\mathrm{m}}$ component (PVDF). For the fact that the depression of $T_{\mathrm{m}}$ of PBSU was very small, we can consider
Table III. Temperatures of crystallization peaks $T_{\mathrm{c}}$ and heats of crystallization $\Delta H_{\mathrm{c}}$ corresponding to the DSC thermograms in Figure 4a

\begin{tabular}{|c|c|c|c|c|}
\hline \multirow{3}{*}{ PBSU/PVDF } & \multicolumn{2}{|c|}{ PBSU } & \multicolumn{2}{|c|}{ PVDF } \\
\hline & $T_{\mathrm{c}, \mathrm{PBSU}}$ & $\Delta H_{\mathrm{c}, \mathrm{PBSU}}$ & $T_{\mathrm{c}, \mathrm{PVDF}}$ & $\Delta H_{\mathrm{c}, \mathrm{PVDF}}$ \\
\hline & ${ }^{\circ} \mathrm{C}$ & $\mathrm{Jg}^{-1}$ & ${ }^{\circ} \mathrm{C}$ & $\mathrm{Jg}^{-1}$ \\
\hline $100: 0$ & 74.0 & 64.2 & - & - \\
\hline $80: 20$ & 72.1 & 46.9 & 106.2 & 6.0 \\
\hline $60: 40$ & 69.8 & 36.1 & 117.6 & 14.6 \\
\hline $40: 60$ & 67.8 & 20.1 & 122.8 & 25.6 \\
\hline $20: 80$ & - & - & 130.9 & 32.7 \\
\hline $0: 100$ & - & - & 133.8 & 41.2 \\
\hline
\end{tabular}

Table IV. Temperatures of melting peaks $T_{\mathrm{m}}$ and heats of melting $\Delta H_{\mathrm{m}}$ corresponding to the DSC thermograms in Figure $4 b$

\begin{tabular}{|c|c|c|c|c|}
\hline \multirow{3}{*}{ PBSU/PVDF } & \multicolumn{2}{|c|}{ PBSU } & \multicolumn{2}{|c|}{ PVDF } \\
\hline & $T_{\mathrm{m}, \mathrm{PBSU}}$ & $\Delta H_{\mathrm{m}, \mathrm{PBSU}}$ & $T_{\mathrm{m}, \mathrm{PVDF}}$ & $\Delta H_{\mathrm{m}, \mathrm{PVDF}}$ \\
\hline & ${ }^{\circ} \mathrm{C}$ & $\mathrm{Jg}^{-1}$ & ${ }^{\circ} \mathrm{C}$ & $\mathrm{Jg}^{-1}$ \\
\hline $100: 0$ & 114.0 & 66.0 & - & - \\
\hline $80: 20$ & 114.1 & 43.4 & 146.1 & 7.9 \\
\hline $60: 40$ & 112.5 & 30.4 & 149.1 & 16.0 \\
\hline $40: 60$ & 109.1 & 18.3 & 151.5 & 22.4 \\
\hline $20: 80$ & 106.6 & 6.2 & 157.6 & 29.7 \\
\hline $0: 100$ & - & - & 158.9 & 45.9 \\
\hline
\end{tabular}

the casting temperature of the blend. The blend solution was cast at an elevated temperature $\left(c a .120^{\circ} \mathrm{C}\right)$ and, at this temperature, the PVDF starts to crystallize immediately, whereas the PBSU cannot crystallize at this high temperature. Similar results were obtained for slow crystallization condition $\left(1^{\circ} \mathrm{C} \mathrm{min}^{-1}\right.$ cooling, see next paragraph) and the discussion will be done later.

Figures 4(a) and (b) show DSC thermograms of the blends during the cooling and the heating process of the program (a), respectively. The DSC thermograms obtained during crystallization $\left(10^{\circ} \mathrm{C} \mathrm{min}^{-1}\right.$ cooling) show two specific crystallization exothermic peaks corresponding to the crystallization of PVDF and PBSU. The crystallization peak temperatures $T_{\mathrm{c}}$ and the enthalpy of crystallization $\Delta H_{\mathrm{c}}$ were composition dependent (Table III). Two distinct DSC melting peaks appeared corresponding to the two specific crystallizations. The higher and the lower-melting peaks are attributed to the melting of PVDF and PBSU phases, respectively. In contrast to the solution-cast blends, PBSU showed single melting peak. The $T_{\mathrm{m}}$ for each component decreased with increasing the fraction of the other component. However, the melting point depression of PBSU was larger than that of solution-cast blends (Table IV). Similar crystallization and melting behavior were observed for the blends crystallized at a cooling rate of $1^{\circ} \mathrm{Cmin}^{-1}$ (program (a)) and the results were summarized in Table $\mathrm{V}$. Only one distinct feature in Table V was that no noticeable changes in the $T_{\mathrm{c}}$ of the PBSU were observed, except for the blend containing more than $80 \%$ PVDF. This constant $T_{\mathrm{c}}$ of the PBSU can be explained as follows; for the extremely slow crystallization condition, such as $1^{\circ} \mathrm{C} \mathrm{min}^{-1}$, the PVDF compo- 
Table V. Crystallization temperatures $T_{\mathrm{c}}$, heats of crystallization $\Delta H_{\mathrm{c}}$, temperatures of melting peaks $T_{\mathrm{m}}$, and heats of melting $\Delta H_{\mathrm{m}}$ of PBSU and PVDF in PBSU/PVDF blends

Samples were crystallized at a cooling rate of $1{ }^{\circ} \mathrm{Cmin}^{-1}$ (program (a) in Figure 1).

\begin{tabular}{|c|c|c|c|c|c|c|}
\hline \multirow{3}{*}{ PBSU/PVDF } & \multicolumn{3}{|c|}{ PBSU } & \multicolumn{3}{|c|}{ PVDF } \\
\hline & $T_{\mathrm{c}, \mathrm{PBSU}}$ & $T_{\mathrm{m}, \mathrm{PBSU}}$ & $\Delta H_{\mathrm{m}, \mathrm{PBSU}}$ & $T_{\mathrm{c}, \mathrm{PVDF}}$ & $T_{\mathrm{m}, \mathrm{PVDF}}$ & $\Delta H_{\mathrm{m}, \mathrm{PVDF}}$ \\
\hline & ${ }^{\circ} \mathrm{C}$ & ${ }^{\circ} \mathrm{C}$ & $\mathrm{Jg}^{-1}$ & ${ }^{\circ} \mathrm{C}$ & ${ }^{\circ} \mathrm{C}$ & $\mathrm{Jg}^{-1}$ \\
\hline $100: 0$ & 86.3 & 113.9 & 82.7 & - & - & - \\
\hline $80: 20$ & 85.8 & 114.0 & 67.0 & 125.6 & 149.1 & 9.9 \\
\hline $60: 40$ & 86.2 & 113.5 & 50.6 & 132.3 & 153.4 & 20.1 \\
\hline $40: 60$ & 83.4 & 112.1 & 21.2 & 138.6 & 157.9 & 28.8 \\
\hline $20: 80$ & 72.9 & 108.1 & 4.7 & 143.1 & 160.8 & 41.0 \\
\hline $0: 100$ & - & - & - & 145.0 & 161.8 & 41.9 \\
\hline
\end{tabular}

nents are completely crystallized before the temperature region of the PBSU crystallization is reached. Therefore, the crystallization of the PBSU molecules occurs in the matrix of PVDF crystals. This result in a small melting point depression and a constant $T_{\mathrm{c}}$ of the PBSU. Further discussion on the crystallization of PBSU in the matrix of PVDF crystals will be given in the section of microscopic observations.

Figures 5(a) and (b) show DSC thermograms of the blends crystallized using program (b) in Figure 1 and the results were summarized in Table VI. Since the cooling rate of the program (b) was faster than that of the program (a) (i.e., $100^{\circ} \mathrm{Cmin}^{-1}$ for program (b) and $10^{\circ} \mathrm{C} \mathrm{min}^{-1}$ or $1^{\circ} \mathrm{C} \mathrm{min}^{-1}$ for program (a)), less time is available for the PVDF melt to crystallize until the blends reach the temperature where PBSU melt starts to crystallize. As a result of this short crystallization time of PVDF, PBSU melt has relatively sufficient time to crystallize when it is compared to the crystallization condition of process (a). Therefore, the magnitude of the melting point depression for PBSU was larger than that slow crystallization conditions (cooling at $10^{\circ} \mathrm{C} \mathrm{min}^{-1}$ or $1^{\circ} \mathrm{C} \min ^{-1}$ as shown in Tables IV and V), whereas that of PVDF was unchanged.

Figure 6 shows DSC thermograms showing cold crystallization and melting endotherms of the blends quenched from the melt using liquid nitrogen (program (c)). The cold crystallization temperature $T_{\mathrm{c}}$ of PBSU increased gradually with PVDF content. However, no noticeable crystallization exothermic peaks of PVDF were observed. It appears that the crystallization of quenched PVDF occurs over the wide temperature ranges, therefore, no noticeable sharp peaks were observed. Such a crystallization behavior of quenched PVDF has appeared in other papers. ${ }^{1,25-26}$ Since both the PBSU and the PVDF molecules are amorphous at $-80^{\circ} \mathrm{C}$ in melt-quenched sample, the amorphous blends experience both crystallization and melting during DSC scanning. In this cold crystallization process, sufficient time is available for the PBSU to crystallize and the actual amorphous fraction of PVDF is larger than that of the sample crystallized from the melt (process (a), (b), and (c)) because PVDF molecules crystallize over the wide temperature ranges above its $T_{\mathrm{g}}$. Therefore, the magnitude of the melting point depression of PBSU was larger than the other fast crystallization conditions. The results are summarized in Table VII. The $T_{\mathrm{m}}$ for PBSU (a)

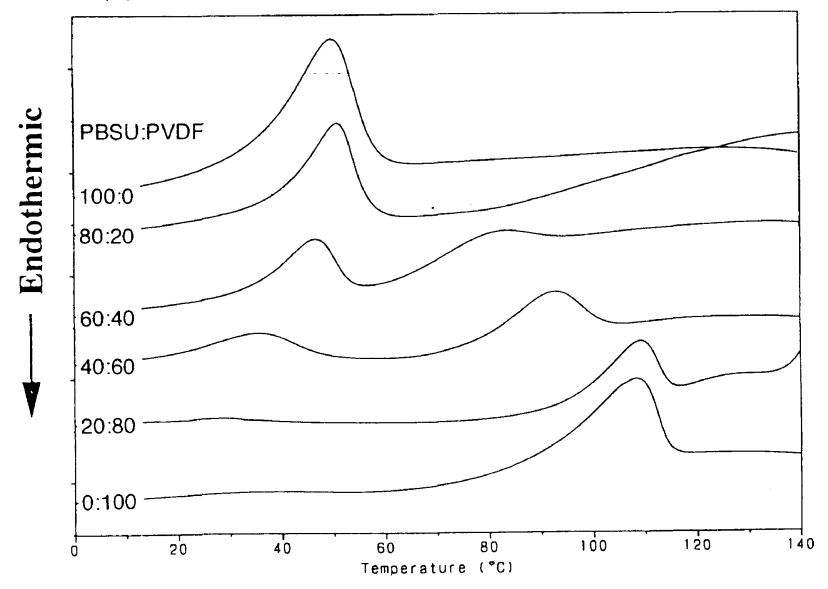

(b)

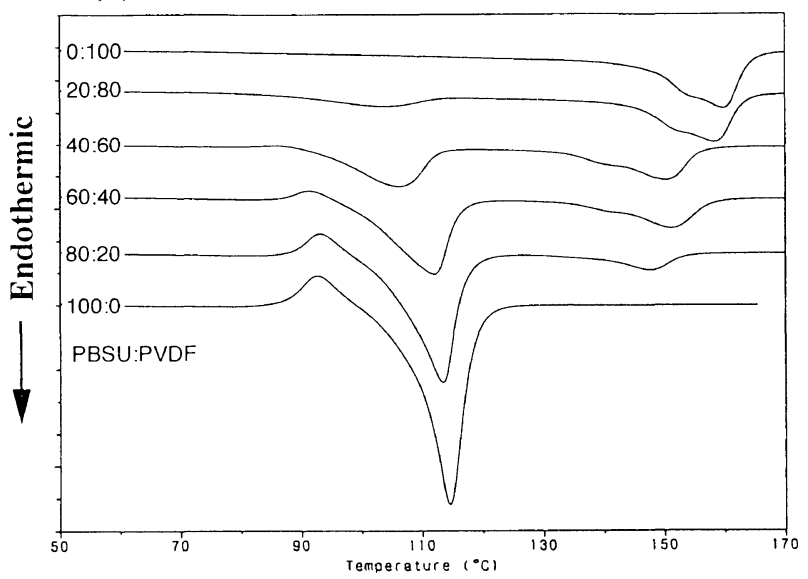

Figure 5. DSC scans showing (a) the crystallization of PBSU/PVDF blends on cooling $100^{\circ} \mathrm{C} \mathrm{min}^{-1}$, (b) the melting endotherms of the samples crystallized on cooling $100^{\circ} \mathrm{C} \mathrm{min}^{-1}$. Scan rate was $20^{\circ} \mathrm{C}$ $\min ^{-1}$.

of the blend with $20 \%$ PVDF was $13.8^{\circ} \mathrm{C}$ lower than that for pure PBSU. However, $T_{\mathrm{m}}$ for PBSU of the blend crystallized at $1^{\circ} \mathrm{C} \mathrm{min}^{-1}$ was only $6^{\circ} \mathrm{C}$ lower than that of pure PBSU (see Table V).

Finally, to compare the effect of cooling rates (i.e., crystallization speed) on the magnitude of the melting point depression for each component, we summarized all the results obtained in this section in Table VIII. We can see that the faster the crystallization speed of the 
Table VI. Crystallization temperatures $T_{\mathrm{c}}$, heats of crystallization $\Delta H_{\mathrm{c}}$, temperatures of melting peaks $T_{\mathrm{m}}$, and heats of melting $\Delta H_{\mathrm{m}}$ of PBSU and PVDF in PBSU/PVDF blends

Samples were crystallized at a cooling rate of $100^{\circ} \mathrm{C} \mathrm{min}^{-1}$ (program (b) in Figure 1).

\begin{tabular}{|c|c|c|c|c|c|c|}
\hline \multirow{3}{*}{ PBSU/PVDF } & \multicolumn{3}{|c|}{ PBSU } & \multicolumn{3}{|c|}{ PVDF } \\
\hline & $T_{\mathrm{c}, \mathrm{PBSU}}$ & $T_{\mathrm{m}, \mathrm{PBSU}}$ & $\Delta H_{\mathrm{m}, \mathrm{PBSU}}$ & $T_{\mathrm{c}, \mathrm{PVDF}}$ & $T_{\mathrm{m}, \mathrm{PVDF}}$ & $\Delta H_{\mathrm{m}, \mathrm{PVDF}}$ \\
\hline & ${ }^{\circ} \mathrm{C}$ & ${ }^{\circ} \mathrm{C}$ & $\mathrm{Jg}^{-1}$ & ${ }^{\circ} \mathrm{C}$ & ${ }^{\circ} \mathrm{C}$ & $\mathrm{Jg}^{-1}$ \\
\hline $100: 0$ & 50.3 & 114.2 & 73.0 & - & - & - \\
\hline $80: 20$ & 50.9 & 113.1 & 52.7 & 125.6 & 147.5 & 7.7 \\
\hline $60: 40$ & 46.1 & 111.7 & 35.0 & 80.9 & 150.8 & 16.8 \\
\hline $40: 60$ & 35.6 & 105.9 & 22.8 & 92.6 & 149.9 & 21.9 \\
\hline $20: 80$ & - & 103.0 & 6.6 & 109.3 & 158.1 & 28.6 \\
\hline $0: 100$ & - & - & - & 108.3 & 159.5 & 38.5 \\
\hline
\end{tabular}

Table VII. Crystallization temperatures $T_{\mathrm{c}}$, heats of crystallization $\Delta H_{\mathrm{c}}$, temperatures of melting peaks $T_{\mathrm{m}}$, and heats of melting $\Delta H_{\mathrm{m}}$ of PBSU and PVDF in PBSU/PVDF blends

The blends were crystallized after quenching into liquid nitrogen from $190^{\circ} \mathrm{C}$.

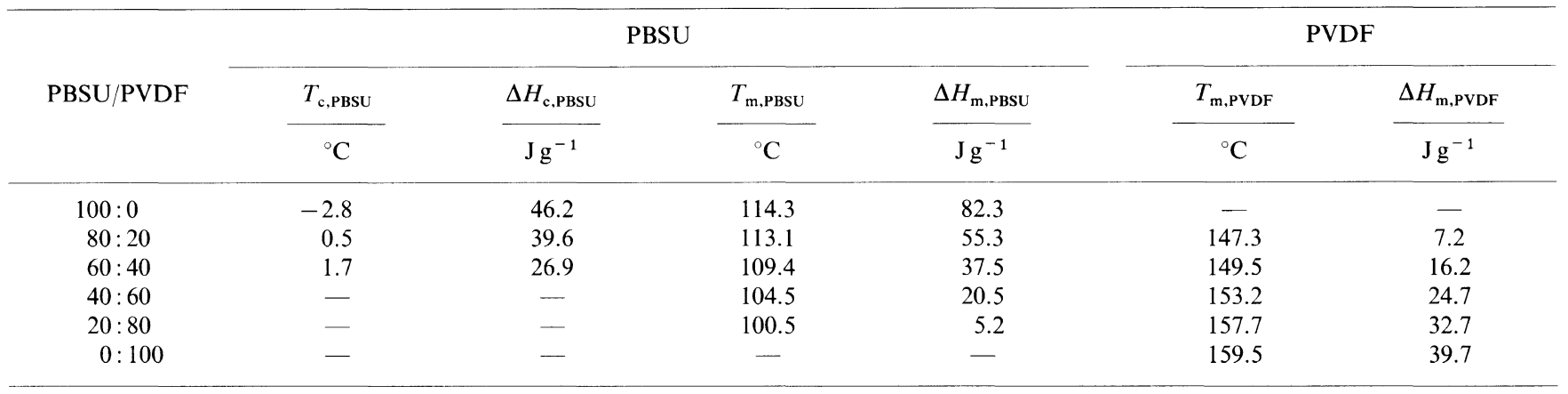

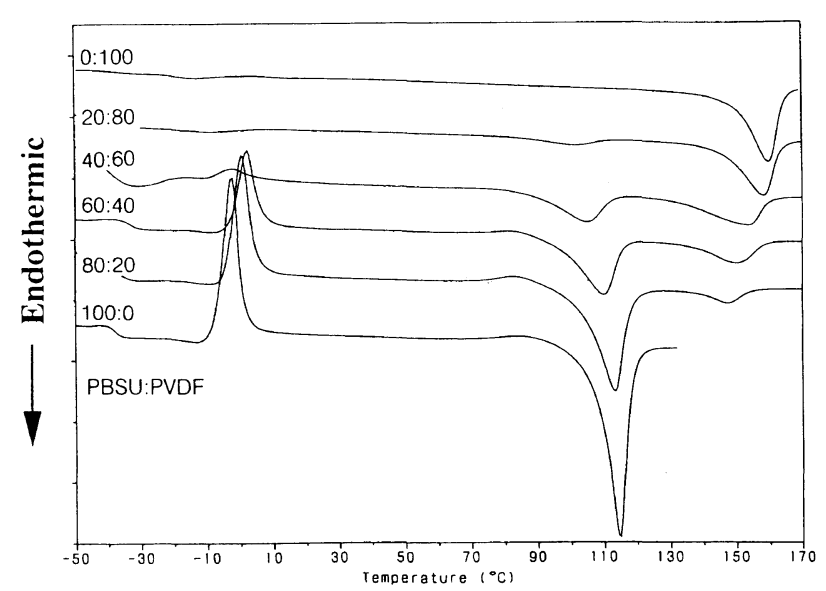

Figure 6. DSC crystallization and melting peaks of PBSU/PVDF blends after quenching in liquid nitrogen (thermal program (c) in Figure 1). Exothermic peaks are corresponding to the crystallization of PBSU. Two endothermic peaks are corresponding to the melting of PBSU and PVDF phase, respectively.

blends, the larger the magnitude of the melting point depression of the PBSU, whereas that of the PVDF is almost unchanged.

The melting point of a polymer is affected not only by thermodynamic factors but also by morphological factors such as the lamellar thickness. To get rid of the morphological contribution to the melting point depression, an equilibrium melting point depression of the blends was analyzed and the results will be discussed in the next section.

\section{Equilibrium Melting Point of PVDF}

The analysis of the melting behavior of a crystalline component in crystalline/amorphous blends is a useful technique in analyzing the miscibility of the blends. In miscible blends, the melting point of the crystalline component is lowered with respect to the pure polymer because of a decrease of the chemical potential of the amorphous phase of the sample. The extent of the melting point depression gives the thermodynamic interaction parameter $\chi_{12}$ in the Flory-Huggins theory. In discussing the Flory-Huggins theory, however, we should use equilibrium melting point data. Melting point depression analysis of crystalline/crystalline blends using FloryHuggins theory also have been reported in the case of $\mathrm{PBA} / \mathrm{PVDF},{ }^{10} \mathrm{PCL} /$ poly(vinylidene chloride), ${ }^{20,21}$ and PHB/PEO. ${ }^{2}$

The Hoffman-Weeks extrapolation method ${ }^{27}$ was used to determine the equilibrium melting point of the blends. The Hoffman-Weeks equation

$$
T_{\mathrm{m}}=\eta T_{\mathrm{c}}+(1-\eta) T_{\mathrm{m}}^{0}
$$

shows a linear relation between $T_{\mathrm{m}}$ and $T_{\mathrm{c}}$. The equilibrium melting temperature $T_{\mathrm{m}}^{0}$ is obtained from the intersection of this line with the line $T_{\mathrm{m}}=T_{\mathrm{c}}$. A value of $\eta=0$ implies that the crystals are perfectly stable, whereas a value of $\eta=1$ reflects inherently unstable crystals.

Figure 7 shows the Hoffman-Weeks plots for the PVDF component in various PBSU/PVDF blends. The results are summarized in Table IX. The DSC melting peak temperatures of the isothermally crystallized samples were used in these plots. Straight lines were drawn and a depression of $T_{\mathrm{m}}$ for the same $T_{\mathrm{c}}$ was ob- 
Table VIII. Effect of cooling rates (i.e., crystallization conditions) on the magnitude of the melting point depression of PBSU and PVDF in PBSU/PVDF blends

\begin{tabular}{|c|c|c|c|c|c|c|}
\hline \multirow{3}{*}{$\begin{array}{l}\text { Crystallization } \\
\text { condition }\end{array}$} & \multicolumn{3}{|c|}{$T_{\mathrm{m}, \mathrm{PBSU}}$} & \multicolumn{3}{|c|}{$T_{\mathrm{m}, \mathrm{PVDF}}$} \\
\hline & PBSU $100 \%$ & PBSU $20 \%$ & $\Delta T_{\mathrm{m}, \mathrm{PBSU}}{ }^{\mathrm{f}}$ & PVDF $100 \%$ & PVDF $20 \%$ & $\Delta T_{\mathrm{m}, \mathrm{PVDF}}{ }^{\mathrm{g}}$ \\
\hline & ${ }^{\circ} \mathrm{C}$ & ${ }^{\circ} \mathrm{C}$ & ${ }^{\circ} \mathrm{C}$ & ${ }^{\circ} \mathrm{C}$ & ${ }^{\circ} \mathrm{C}$ & ${ }^{\circ} \mathrm{C}$ \\
\hline Solution-cast ${ }^{a}$ & 114.9 & 112.4 & 2.5 & 157.4 & 149.1 & 8.3 \\
\hline $1^{\circ} \mathrm{C} \mathrm{min}^{-1}$ cooling ${ }^{\mathrm{b}}$ & 114.0 & 108.0 & 6.0 & 161.8 & 149.1 & 12.7 \\
\hline $100^{\circ} \mathrm{C} \mathrm{min}^{-1}$ cooling $^{\mathrm{d}}$ & 114.2 & 103.0 & 11.2 & 159.5 & 147.5 & 12.0 \\
\hline Quench in liq. $\mathrm{N}_{2}{ }^{\mathrm{e}}$ & 114.3 & 100.5 & 13.8 & 159.5 & 147.3 & 12.2 \\
\hline
\end{tabular}

${ }^{\mathrm{a}}$ Data from Table II. ${ }^{\mathrm{b}}$ Data from Table V. ${ }^{\mathrm{c}}$ Data from Table IV. ${ }^{\mathrm{d}}$ Data from Table VI. ${ }^{\mathrm{e}}$ Data from Table VII. ${ }^{\mathrm{f}} T_{\mathrm{m}, \mathrm{PBSU}} 100 \%-T_{\mathrm{m}, \mathrm{PBSU}} 20 \%{ }^{\circ}$ ${ }^{\mathrm{g}} T_{\mathrm{m}, \mathrm{PVDF}} 100 \%-T_{\mathrm{m}, \mathrm{PVDF}} 20 \%$.

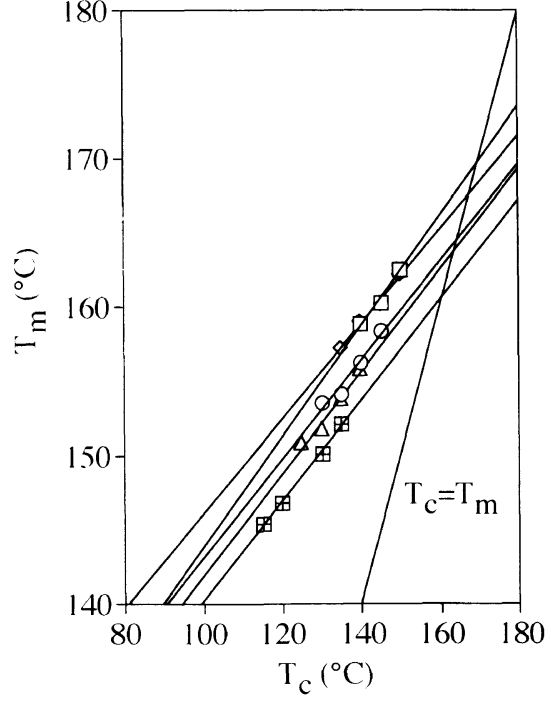

Figure 7. Hoffman-Weeks plots for PVDF in PBSU/PVDF blends. $\square$, PVDF $100 \%$; $\diamond$, PVDF $80 \%$; O, PVDF $60 \%$; $\triangle$, PVDF $40 \%$; 円, PVDF $20 \%$.

served. The value of $T_{\mathrm{m}}^{0}$ of PVDF decreased with PBSU content as in the case of the blends crystallized from the melt. For the blends containing 20\% PVDF, for example, $T_{\mathrm{m}}^{0}$ was $9^{\circ} \mathrm{C}$ lower than that of pure PVDF. The slope $\eta$ of PVDF was almost unchanged with PBSU content except for the pure PVDF. It is important to remind that the PBSU phase is in melt state at the temperature where the PVDF crystallization occurs. We have reported a large equilibrium melting point depression of $\mathrm{PHB}$ in $\mathrm{PHB} /$ poly(vinylidene chloride-co-acrylonitrile) (P(VDCAN)) blends where the depression of $T_{\mathrm{m}}^{0}$ was as large as $30^{\circ}$ C. ${ }^{9}$ In PHB/P(VDC-AN) blends, the slope $\eta$ of PHB increased with noncrystallizable $\mathrm{P}(\mathrm{VDC}-\mathrm{AN})$ content. This increase of the slope $\eta$ implied that the PHB crystals are more unstable, i.e., have thinner lamellar thickness with larger $\mathrm{P}(\mathrm{VDC}-\mathrm{AN})$ content. This morphological effect should cause the drastic melting point depression observed in PHB/P(VDC-AN) blends. Therefore, relatively small depression of $T_{\mathrm{m}}^{0}$ of the PVDF in PBSU/ PVDF blends is related to the almost constant value of $\eta$ in the blends. The stability of PVDF crystals is unchanged by blending PBSU. This implies that morphological effect of the melting point of PVDF crystal in the blend is small and this lead to the small depression of $T_{\mathrm{m}}^{0}$ of the PVDF in PBSU/PVDF blends.
Table IX. Results of the Hoffman-Weeks analysis of the PVDF component in PBSU/PVDF blends

\begin{tabular}{ccc}
\hline PBSU/PVDF & $T_{\mathrm{m}}^{0} /{ }^{\circ} \mathrm{C}$ & $\eta$ \\
\hline $100: 0$ & 169.7 & 0.37 \\
$80: 20$ & 167.6 & 0.32 \\
$60: 40$ & 164.5 & 0.33 \\
$40: 60$ & 163.6 & 0.34 \\
$20: 80$ & 160.6 & 0.34 \\
\hline
\end{tabular}

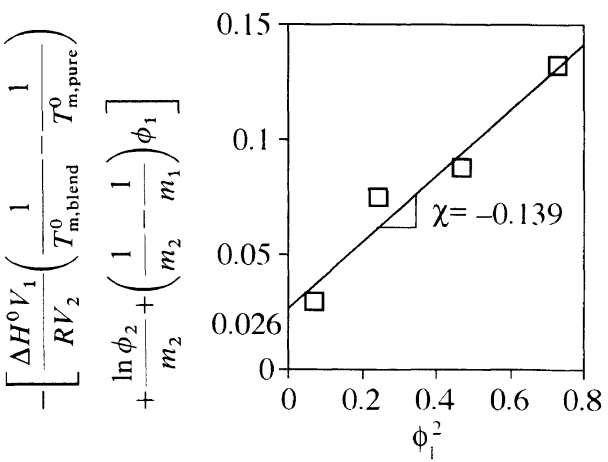

Figure 8. Melting point depression of PVDF in PBSU/PVDF blends as a function of blend composition, plotted according to eq 2 .

According to the Flory-Huggins theory, ${ }^{1,28}$ the melting point depression of a crystalline polymer in a mixture with non-crystallizable polymeric diluent is expressed by

$$
\begin{aligned}
& -\left[\frac{\Delta H^{0} V_{1}}{R V}\left(\frac{1}{T_{\text {m,blend }}^{0}}-\frac{1}{T_{\mathrm{m}, \text { pure }}^{0}}\right)+\frac{\ln \phi_{2}}{m_{2}}\right. \\
& \left.+\left(\frac{1}{m_{2}}-\frac{1}{m_{1}}\right) \phi_{1}\right]=\chi_{12} \phi_{1}^{2},
\end{aligned}
$$

where $T_{\mathrm{m} \text {,pure }}^{0}$ and $T_{\mathrm{m} \text {,blend }}^{0}$ are the equilibrium melting points of the crystalline polymer in the pure state and in the blends, respectively, $\Delta H^{0}$ is the heat of fusion of the crystalline component, $V_{i}$ is the molar volume of the polymer unit, and $m_{i}$ and $\phi_{i}$ are degree of polymerization and volume fraction, respectively, of component $i$. Subscripts 1 and 2 refer to the PBSU melt and PVDF, respectively. If $\chi_{12}$ is independent of the blend composition, a plot of the left-hand side of eq 2 vs. $\phi_{1}^{2}$ gives a straight line passing through the origin with a slope equal to $\chi_{12}$. The plot of the values of $T_{\mathrm{m}}^{0}$ in Table IX according to eq 2 is shown in Figure 8. The following 


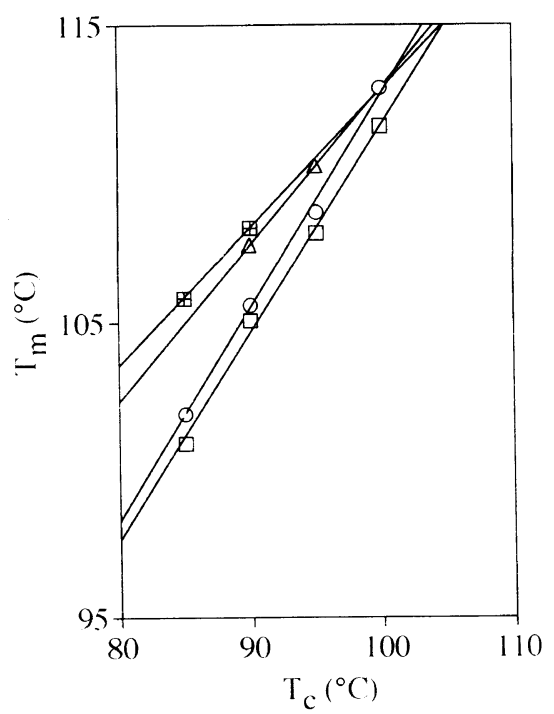

Figure 9. Hoffman-Weeks plots for PBSU in PBSU/PVDF blends. $\square$, PBSU $100 \%$; O, PBSU $80 \%$; $\triangle$, PBSU $60 \%$; $\boxplus$, PBSU $40 \%$.

parameters were used to calculate the left hand side of eq 2: $\Delta H^{0}=6.0 \mathrm{~kJ} \mathrm{~mol}^{-1}, V_{1}=138.7 \mathrm{~cm}^{3} \mathrm{~mol}^{-1}, V_{2}=$ $36.4 \mathrm{~cm}^{3} \mathrm{~mol}^{-1}, m_{1}=307$, and $m_{2}=8938$. Group contribution method was used in estimating the molar volume of PBSU, $V_{1} \cdot{ }^{29}$ The experimental points were fitted to a line with an intercept of 0.026 and a slope $\left(\chi_{12}\right)$ of -0.139 . The negative value of $\chi_{12}$ indicates that these blends form thermodynamically miscible mixtures above the melting points of PVDF. Finally, we can consider two possibilities for the fact that the fitted line in Figure 8 does not pass through the origin. One is the composition dependence of $\chi_{12}$ itself. The other is the thermal instability of PBSU; biodegradable polyesters such as PHB and PBSU are known as thermally unstable above their melting temperature. This thermal instability changes the degree of polymerization $m_{1}$ in the left-hand side of eq 2 .

\section{Equilibrium Melting Point of PBSU}

In the previous section, we have shown the melting point depression analysis of PVDF using equilibrium melting points. Since the PBSU molecules are in the amorphous state at the temperature range where the isothermal crystallization of the PVDF occurs, the equilibrium melting behavior of PVDF in PBSU/PVDF blend was similar to that of PVDF in amorphous/crystalline blend such as PMMA/PVDF blend. ${ }^{1}$ However, the equilibrium melting behavior of the low- $T_{\mathrm{m}}$ component PBSU was substantially different from the equilibrium melting behavior of the high- $T_{\mathrm{m}}$ component PVDF.

Figure 9 shows the Hoffman-Weeks plots for the PBSU component in various PBSU/PVDF blends. The DSC melting peak temperatures of the isothermally crystallized samples were used in these plots. The blends containing more than $40 \%$ of PBSU showed melting peaks of PBSU. For a given blend composition, $T_{\mathrm{m}}$ of PBSU increased with $T_{\mathrm{c}}$ and straight lines were drawn as in the case of PVDF. However, for a given $T_{\mathrm{c}}$, the value of $T_{\mathrm{m}}$ of PBSU increased with PVDF content. For the blends containing $60 \%$ PVDF crystallized at $90^{\circ} \mathrm{C}$, $T_{\mathrm{m}}$ of PBSU was $3^{\circ} \mathrm{C}$ higher than that of pure PBSU.
Therefore, melting point depression analysis using Flory-Huggins theory has no meaning here. From the thermodynamic point of view, $T_{\mathrm{m}}$ of the blend should be lower than that of pure state. Similar results were found by Manley et al. ${ }^{10}$ in the case of PBA/PVDF blends. They explained that in the temperature range of low- $T_{\mathrm{m}}$ component (PBA) crystallization, high- $T_{\mathrm{m}}$ component (PVDF) is semicrystalline and only the amorphous fraction could act as a diluent of low- $T_{\mathrm{m}}$ component. This means that the actual volume fraction of high- $T_{\mathrm{m}}$ component in the liquid phase is much smaller. Probably, this can explain our result. However, we can consider another possibility which was suggested by Blumm et $a l .{ }^{30}$ in the case of bacterially produced PHB and poly(L-lactide) (PLLA) blends. They examined melting behavior of low- $T_{\mathrm{m}}$ component (PLLA) which was grown in the interlamellar region of high- $T_{\mathrm{m}}$ component (PHB) using polarized light microscopy. They observed the increase of the melting point of PLLA in the presence of PHB and they explained that the interlocked crystals in the interlamellar region of $\mathrm{PHB}$ is the main cause of this melting point rise. We suppose that the above two explanations are all applicable to our case at this stage. Concerning the observed melting point rise of PBSU component, we discuss it further in Discussion section.

\section{Morphology and Spherulitic Growth Rate of PVDF}

Figure 10 shows the spherulitic morphologies of PVDF at various blend compositions. The spherulite of the PVDF with $M_{w}=572000$ was so small that it was difficult to observe the spherulitic morphology (see Figure 10(a)). Therefore, we report the spherulitic morphologies of PVDF with $M_{w}=140000$ here. The blends were crystallized at $150^{\circ} \mathrm{C}$ from the melt. The crystallization temperature $T_{\mathrm{c}}=150^{\circ} \mathrm{C}$ is $\mathrm{ca} .35^{\circ} \mathrm{C}$ higher than the melting point of pure PBSU, therefore, only PVDF is crystallizable at this temperature. All the blends containing more than $40 \%$ PVDF showed spherulitic morphologies, and no PBSU domain was found in the spherulites. All the spherulites showed maltese cross and the blend samples showed concentric extinction bands. The band spacings of the PVDF spherulites were increased with increasing PBSU content. Similar behavior has been found in the case of PBA/PVDF blends by Manley et al. ${ }^{10,11}$ These banded spherulitic structures are originated from the cooperatively twisted lamellae in the blends and the band spacings usually decrease with increasing noncrystalline component. ${ }^{31-33}$ However, the results obtained in this study is contrary to the former findings. Manley et al. explained this contrary in their PBA/PVDF blends ${ }^{11}$ that the growth rate of the spherulite is related to this phenomenon, i.e., band spacings increases with decreasing crystal growth rates. However, the reason is still unclear.

The diameter $D$ of isothermally crystallized spherulites increased linearly with crystallization time. The growth rate $G$ was calculated as $G=\mathrm{d} D / \mathrm{d} t$ for various crystallization temperature $T_{\mathrm{c}}$. The results for different PVDF content are shown in Figure 11. The value of $G$ was independent of the size of the spherulites during the crystallization. If PBSU molecules are rejected by the growing PVDF lamellae, the growth rate should decrease 

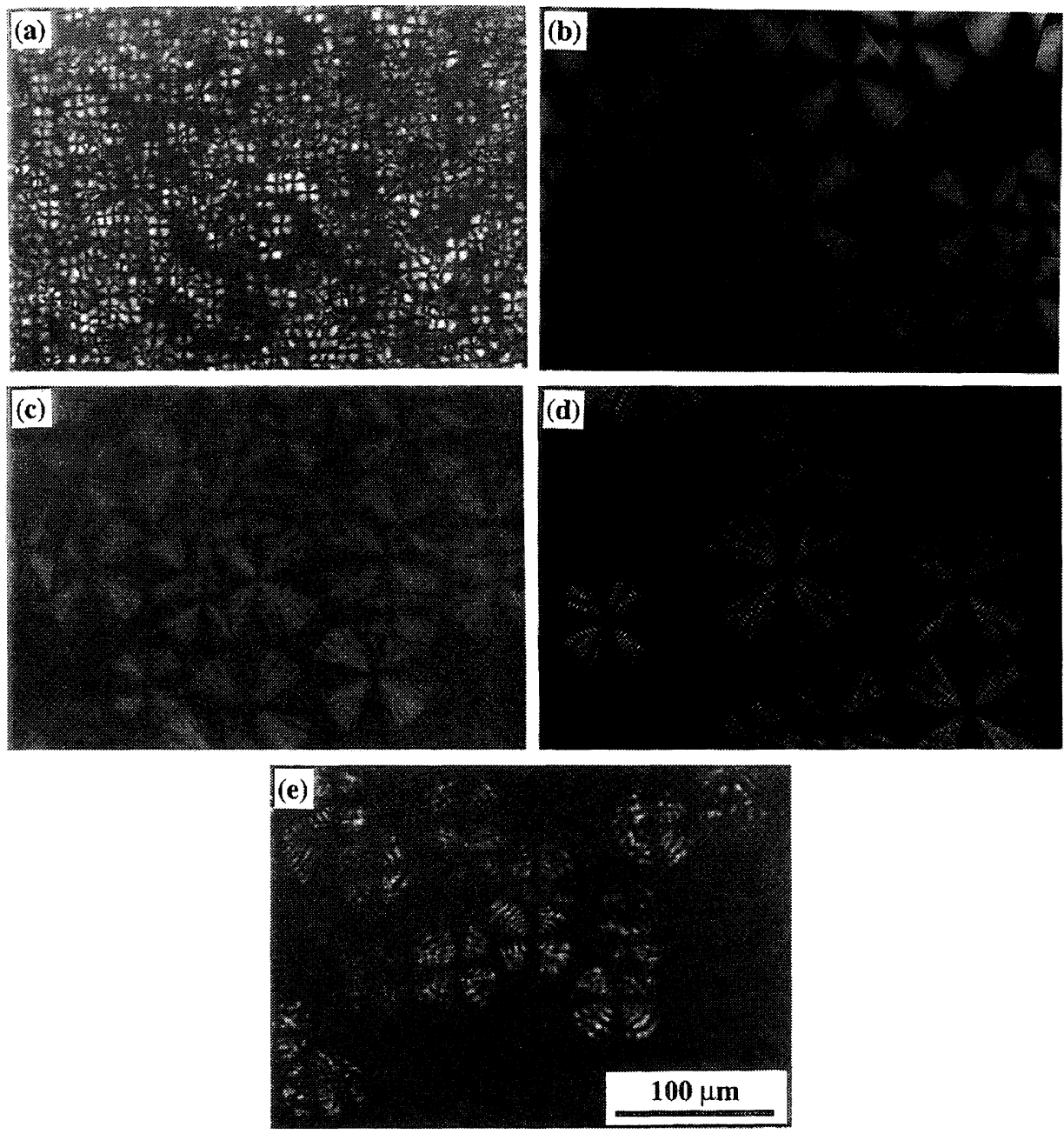

Figure 10. Optical micrographs (same magnification, $\mathrm{bar}=100 \mu \mathrm{m}$ ) of the spherulites of PVDF in PBSU/PVDF blends. Crystallization temperature was $150^{\circ} \mathrm{C}$. (a) PVDF $100 \%, M_{w}=572000$; (b) PVDF $100 \%$; (c) PVDF $80 \%$; (d) PVDF $60 \%$; (e) PVDF $40 \%$. The molecular weight of the PVDF was 140000 , except for the sample (a).

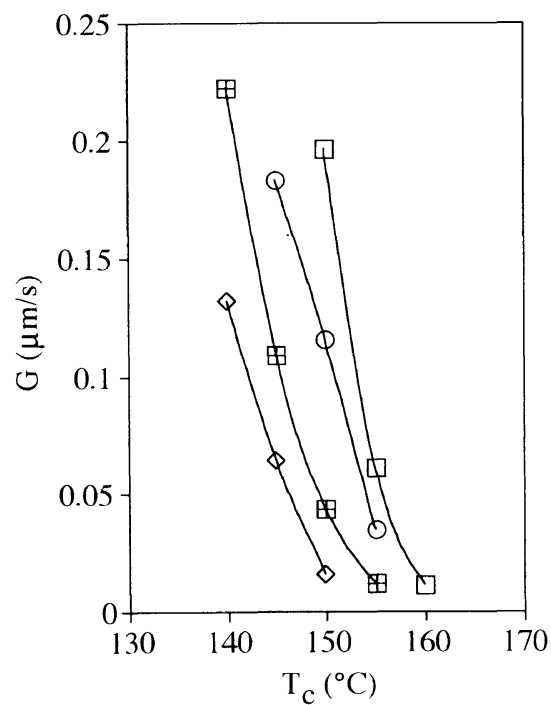

Figure 11. Spherulitic growth rate $G$ of PVDF $v s$. crystallization temperature $T_{\mathrm{c}}$ for PBSU/PVDF blends. The molecular weight of the PVDF was 140000 . $\square$, PVDF $100 \%$; O, PVDF $80 \%$; 田, PVDF $60 \%$; $\diamond$, PVDF $40 \%$.

because of the increase of the diluent (PBSU melt) concentration at the growth front. This causes a marked reduction in the growth rate and the flattening of the

Polym. J., Vol. 30, No. 4, 1998 round spherulite profile. However, such flattening was not observed for the blends containing more than $50 \%$ PVDF. However, for the blends containing less than $40 \%$ PVDF, flattening of the round spherulite profile was observed at the later stage of the crystallization. The growth rate $G$ of PVDF decreased with PBSU content.

The results of microscopic observations of the blends containing more than $40 \%$ PVDF indicates that, during crystallization, the PBSU melt are rejected to the interlamellar regions of PVDF spherulites, where they form miscible mixtures with PBSU melt molecules. However, in the PBSU rich blend, some PBSU molecules exist in the interspherulitic region (see Figure 14 (c)). The crystallization behavior of PBSU molecules remaining in the crystallized PVDF matrix will be discussed in the next section.

\section{Morphology and Spherulitic Growth Rate of PBSU}

In general, the observation of the spherulitic growth of low- $T_{\mathrm{m}}$ component in crystalline/crystalline blend is very difficult because the low $-T_{\mathrm{m}}$ component must crystallize in the matrix of high- $T_{\mathrm{m}}$ component crystals. Therefore, only tiny crystals of low- $T_{\mathrm{m}}$ component can grow in the interlamellar regions of the high- $T_{\mathrm{m}}$ component spherulites. Although the spherulitic growth rates of high- $T_{\mathrm{m}}$ component were reported in several crys- 

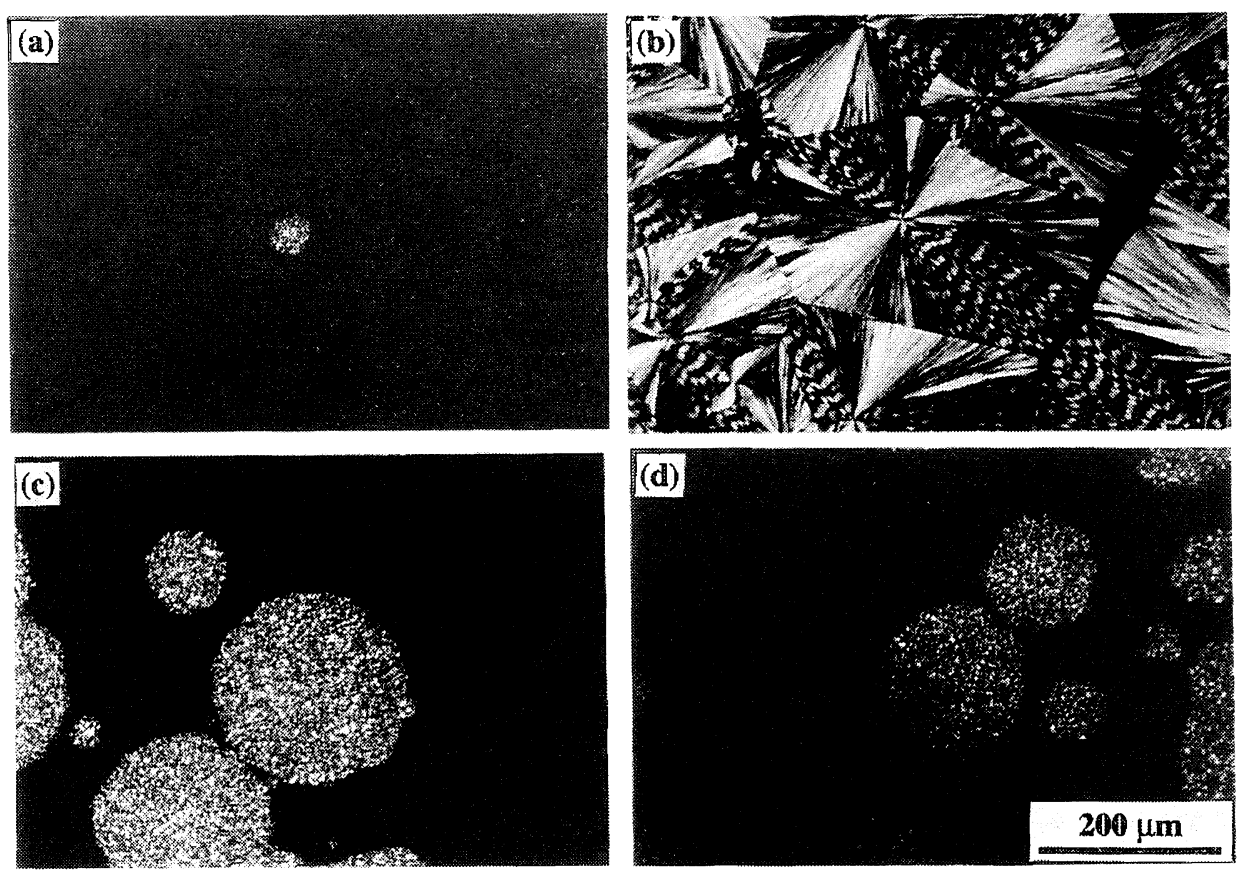

Figure 12. Optical micrographs (same magnification, $b a r=200 \mu \mathrm{m}$ ) of the spherulites of PBSU in PBSU/PVDF blends. Crystallization temperature was $90^{\circ} \mathrm{C}$. (a) initial PVDF morphology of PBSU/PVDF (60:40) blend after 100 s at $90^{\circ} \mathrm{C}$; (b) PBSU $100 \%$; (c) PBSU $80 \%$; (d) PBSU $60 \%$.

talline/crystalline blend (e.g., PCL/PVDC, ${ }^{20,21} \mathrm{PHB} /$ PEO, ${ }^{22}$ and $\left.\mathrm{PBA} / \mathrm{PVDF}^{11}\right)$, the observations of the spherulitic morphologies of the low- $T_{\mathrm{m}}$ component were unsuccessful.

In our PBSU/PVDF system, however, the observation of the low- $T_{\mathrm{m}}$ component, PBSU, was possible because the nucleation frequency of PBSU remained very low in spite of the presence of the PVDF crystals and the PBSU spherulite grows very fast compared to PVDF. This leads to a large spherulite of PBSU which grows in the order of several millimeters (see Figure 12). We have reported similar phenomenon in PCL/carbon black system $^{33}$ where PCL spherulites grow in the matrix of carbon black particles and this low value of nucleation frequency is a characteristics of biodegradable polyesters. ${ }^{9,22,31,34-37}$

Figure 12 shows the spherulitic morphologies of PBSU at various blend compositions. It is unavoidable that the PVDF component partially crystallizes before the temperature region of PBSU crystallization $\left(90^{\circ} \mathrm{C}\right.$ in this case) is reached. However, by suppresing the size of PVDF crystals, we can minimize the effect of PVDF crystals in the crystallization of PBSU. This was achieved by cooling the blend from the melt to $T_{\mathrm{c}}$ of PBSU $\left(80-100^{\circ} \mathrm{C}\right)$ as soon as possible $\left(\mathrm{ca} .90^{\circ} \mathrm{C} \mathrm{min}^{-1}\right)$. It is clearly seen in Figure 12(a) that a spherulite of PBSU from the $60: 40$ blend grows in the background of bright PVDF spots. For the blends containing more than $60 \%$ PBSU spherulitic morphologies were observed. However, the blends containing less than 50\% PBSU spherulites were in irregular shape and it was impossible to distinguish the growth front of PBSU against the bright background of PVDF crystals. No maltese cross or extinction bands were observed in the blends. On the other hand, pure PBSU showed clear maltese cross and extinction bands. We suppose that PVDF crystals interrupted the lamellar twisting or the observation of maltese

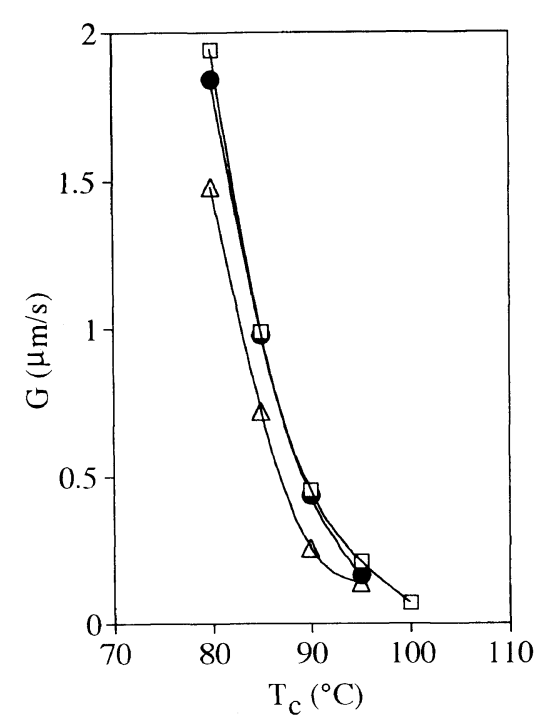

Figure 13. Spherulitic growth rate $G$ of PBSU vs. crystallization temperature $T_{\mathrm{c}}$ for PBSU/PVDF blends. $\square$, PBSU $100 \%$; $\bullet$, PBSU $80 \% ; \triangle$, PBSU $60 \%$.

cross.

Figure 13 shows the spherulitic growth rate $G$ of isothermally crystallized PBSU with different blend composition. The value of $G$ was independent of the size of the spherulites during crystallization as in the case of PVDF. The growth rate $G$ of PBSU decreased very slightly with PVDF content. The growth rate of the blends containing $80 \%$ PBSU was almost the same as that of pure PBSU. The growth rate of PBSU containing $60 \%$ PBSU was reduced to $70 \%$ of pure PBSU at a given $T_{\mathrm{c}}$. However, the growth rate of PVDF containing $60 \%$ PVDF was reduced to as much as $25 \%$ of pure PVDF (see Figure 10). Such a small reduction in the growth rate of PBSU can be explained by considering the concentration of the PBSU in the PVDF matrix. Since 

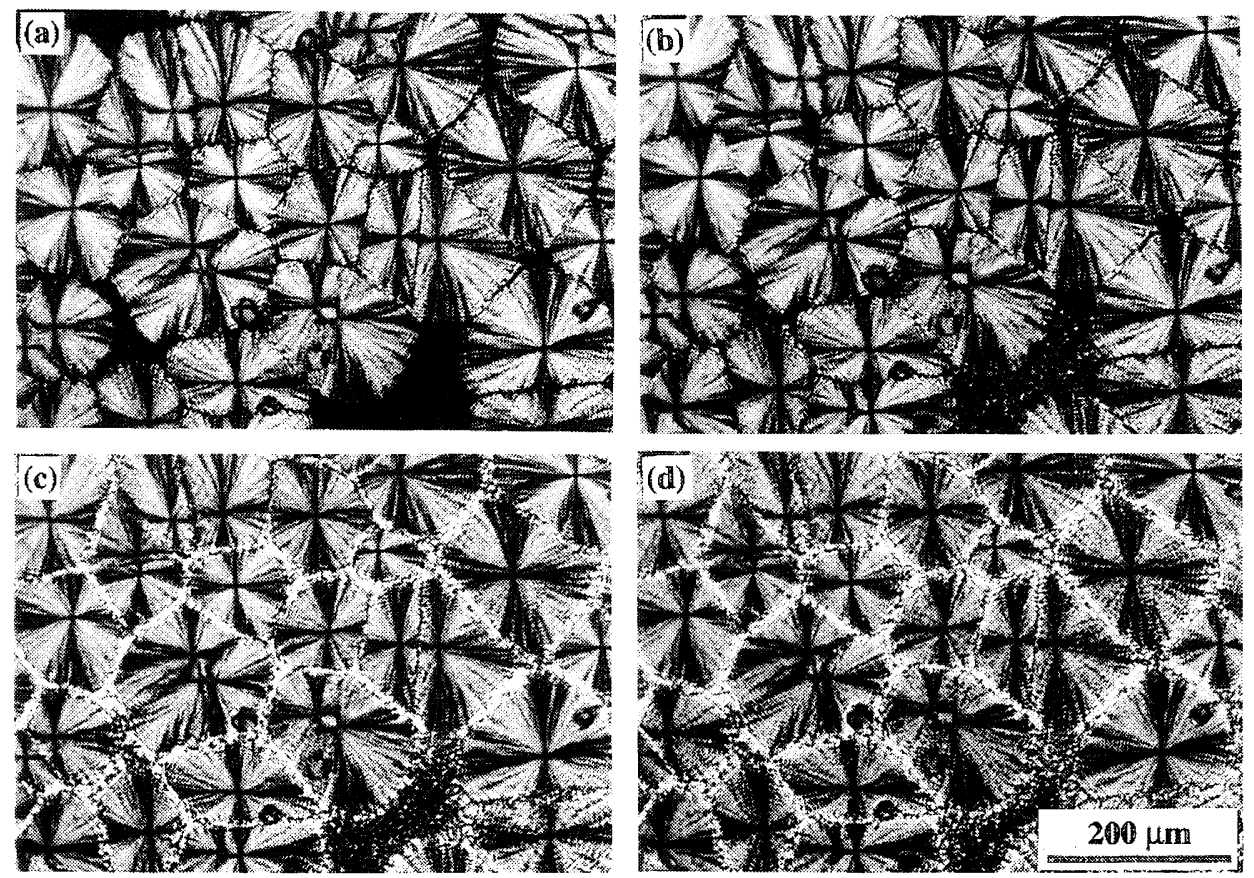

Figure 14. Optical micrographs (same magnification, bar $=200 \mu \mathrm{m}$ ) of PBSU/PVDF (40:60) showing the crystallization of PBSU in the matrix of PVDF crystals. Thermal program (d) was used in the crystallization process (Figure 1). (a) initial PVDF spherulites at $150^{\circ} \mathrm{C}$; (b) initiation of the crystallization of PBSU phase, micrograph was taken immediately after the sample was cooled at $100^{\circ} \mathrm{C} \mathrm{min}{ }^{-1}$ to $90^{\circ} \mathrm{C}$; $(\mathrm{c})$ crystallization of PBSU phase in the interspherulitic regions. Micrograph was taken just after 2 min at $90^{\circ} \mathrm{C}$; (d) crystallization of PBSU phase in the interlamellar regions of PVDF. Micrograph was taken after $2 \mathrm{~h}$ at $90^{\circ} \mathrm{C}$. All the micrographs were taken at the same section of the sample.

PVDF phase is already crystallized at temperatures where crystallization of PBSU occurs, actual concentration of PBSU is higher than the initial volume fraction. This concentration effect compensates lagre reduction of the growth rate of PBSU in the matrix of PVDF. Concerning the concentration effect of the growth rate of PBSU in the PVDF crystals, we also discuss further in Discussion section.

\section{Specific Interaction in the Blends}

Since the miscibility in polymeric blends is due to specific interaction between the two constituent polymers, a certain type of molecular interaction must be present in PBSU/PVDF blends. Coleman et al. have tried to specify the polymer-polymer interaction in PCL/ $\mathrm{PVC}^{38}$ and PCL/PVDC ${ }^{39}$ using fourier transform infrared spectroscopy (FT-IR). They observed a shift of the carbonyl band of PCL. In the case of PCL/PVC blends, the miscibility is due to hydrogen bonding between the $\alpha$-hydrogen atoms of PVC and the carbonyl groups of PCL. In the present study, however, we should consider another interactions since PBSU does not contain $\alpha$-hydrogen. The carbonyl group of PBSU is obviously involved in the molecular interaction as in the case of the PCL/PVDC system, whereas the corresponding site on the PVDF is not clear. Manley et al. ${ }^{10}$ have reported FT-IR study of the miscible PBA/PVDF blends in which PBA has carbonyl group and PVDF has halide $F$ as in the case of our PBSU/PVDF system. They suggested that the miscibility in PBA/PVDF blends is due to the dipole-dipole interaction between the carbonyl groups of PBA and the $\mathrm{C}-\mathrm{F}$ groups of PVDF. We believe that the same interaction, the dipole-dipole interaction between the carbonyl groups of the PBSU and $\mathrm{C}-\mathrm{F}$ groups of PVDF, is the main cause of the miscibility appeared in our case. To verify the specific interaction in PBSU/PVDF blends, further studies on the miscibility of various blends of biodegradable polyesters with vinylidene halides are now in progress.

\section{DISCUSSION}

\section{Analysis of the Crystallization of PBSU in the Matrix of PVDF Crystals}

So far, we have seen a unique crystallization and melting behavior of PBSU in PBSU/PVDF blends. It is evident from the results shown in this article that the presence of partially crystallized PVDF phase is the main cause of the unusual crystallization behavior of PBSU: (i) the magnitude of the melting point depression of PBSU was changed strongly with cooling rate (Table VI), (ii) for a given $T_{\mathfrak{c}}$, the melting point of PBSU increased with PVDF, in contrast to the decrease of the melting point in usual amorphous/crystalline blends (Figure 9), (iii) the spherulitic growth rate $G$ of PBSU decreased very slightly with PVDF at a given $T_{\mathrm{c}}$ (Figure 13).

The foregoing discussions have been based on the assumption that, during the crystallization of PVDF, the PBSU is rejected to the interlamellar or interspherulitic regions of PVDF spherulites and the PVDF phase is already crystallized at the temperature where crystallization of PBSU occurs. We observed the crystallization behavior of PBSU in the matrix of PVDF crystals with an optical microscope. Figure 14 shows polarized optical micrographs of PBSU/PVDF $(40: 60)$ blend. The micrographs were obtained during the two-step crystallization as shown in Figure 1(d). Figure 14(a) shows spherulitic morphology of PVDF after $2 \mathrm{~h}$ at $T_{\mathrm{c}}=150^{\circ} \mathrm{C}$. All the spherulites showed maltese cross and concentric extinction bands as already shown in Figure 10. Figure 14(b) 
represents the same section of the sample, taken immediately after the samples were cooled at $100^{\circ} \mathrm{C} \mathrm{min}^{-1}$ to $90^{\circ} \mathrm{C}$. No PBSU phase is seen in this instant of the crystallization of PBSU at $90^{\circ} \mathrm{C}$. However, interesting micrograph was taken after just $5 \mathrm{~min}$ at $90^{\circ} \mathrm{C}$ (Figure $14(c))$. It is seen that the PBSU crystallized completely in the interspherulitic regions (e.g., changes in the brightness) and the speed of crystallization was so fast that all the interspherulitic regions were filled with PBSU crystals within $5 \mathrm{~min}$ at $90^{\circ} \mathrm{C}$ (See Figure 13, the spherulitic growth rate of PBSU in $60: 40$ blend quenched from the melt to $T_{\mathrm{c}}=90^{\circ} \mathrm{C}$ was as slow as $0.25 \mu \mathrm{m} \mathrm{s}^{-1}$ ). Figure 14(d) represents the same place after $2 \mathrm{~h}$ at $90^{\circ} \mathrm{C}$. Crystallization of PBSU within the spherulite of PVDF was clearly observed, i.e., the brightness of PVDF domain became brighter than that in Figures 14(b) and (c). This fact means that the PBSU in the interspherulitic regions crystallizes instantly (Figure 14(c)), after the PBSU in the interlamellar region of PVDF crystallizes slowly (Figure 14(d)). We suppose that the PBSU crystals in the interlamellar region of PVDF is related to the melting point rise as discussed in the section of equilibrium melting point of PBSU. Similar morphology was observed in PBSU/PVDF $(60: 40)$ blends showing the same morphological behavior. Similar microscopic observations have been reported by Manley et al. ${ }^{11}$ with PBA/ PVDF system.

To verify the crystallization behavior of PBSU shown in Figure 14, we analyzed the isothermal bulk crystallization kinetics (Avrami analysis) of both PVDF and PBSU. Samples were maintained at $190^{\circ} \mathrm{C}$ for $5 \mathrm{~min}$ and then cooled to a given $T_{\mathrm{c}}\left(150^{\circ} \mathrm{C}\right.$ for PVDF and $90^{\circ} \mathrm{C}$ for PBSU) at $100^{\circ} \mathrm{C} \mathrm{min}^{-1}$. The weight fraction, $X_{t}$, of the crystalline component crystallized at time $t$ was calculated using the relation:

$$
X_{t}=\frac{\int_{0}^{t}\left(\frac{\mathrm{d} H}{\mathrm{~d} t}\right) \mathrm{d} t}{\int_{0}^{\infty}\left(\frac{\mathrm{d} H}{\mathrm{~d} t}\right) \mathrm{d} t}
$$

where the integral in the numerator is the heat generated at time $t$ and the denominator is the total heat when the crystallization is completed. The Avrami exponent $n$ was calculated by using the Avrami equation ${ }^{40}$ :

$$
X_{t}=1-\exp \left(-k t^{n}\right)
$$

where $n$ is a parameter depending on the geometry of the growing crystals and on the nucleation process. The values $n$ were determined from the slope of the straight lines obtained by plotting $\log \left[-\ln \left(1-X_{t}\right)\right] v s$. $\log t$. Figures 15 and 16 show results of this plot for PVDF and PBSU, respectively. The values of $n$ were summarized in Tables $\mathrm{X}$ and XI. Contrary to the theoretical prediction, ${ }^{40}$ the values of $n$ were non-integer. Similar non-integer behavior was obtained by Paglia et al. ${ }^{7}$ in $\mathrm{PHB} /$ poly(epichlorohydrin) blends. They explained that this non-integer value of $n$ as the presence of mixed growth and/or surface nucleation mode. The Avrami exponents of PVDF in Table $\mathrm{X}$ were unchanged in the blends. This means that the nucleation and the growth of crystal of PVDF are not affected by blending PBSU. This result is consistent with the microscopic observa-

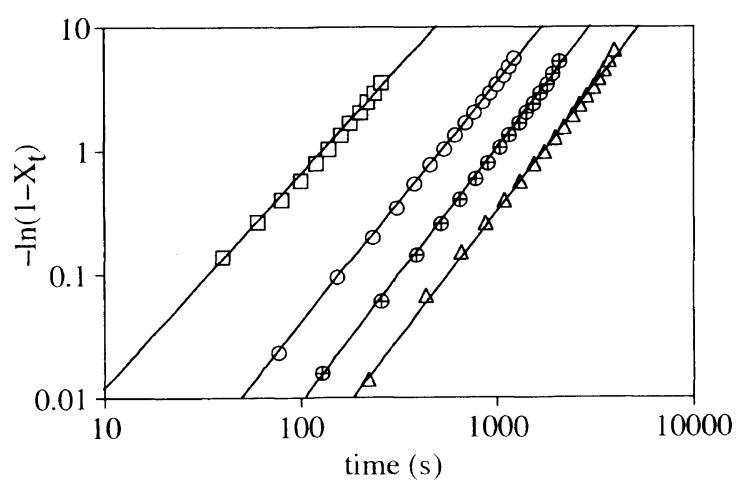

Figure 15. Avrami plots for PVDF at various blend compositions. $\square$, PVDF $100 \%$; O, PVDF $80 \%$; $\oplus$, PVDF $60 \%$; $\triangle$, PVDF $40 \%$. Crystallization temperature of PVDF was $150^{\circ} \mathrm{C}$.

Table X. Values of Avrami exponents $n$ for PVDF at various blend compositions

Crystallization temperature was $150^{\circ} \mathrm{C}$.

\begin{tabular}{cc}
\hline PBSU/PVDF & Avrami exponent, $n$ \\
\hline $0: 100$ & 1.7 \\
$20: 80$ & 2.0 \\
$40: 60$ & 2.1 \\
$60: 40$ & 2.1 \\
\hline
\end{tabular}

Table XI. Values of Avrami exponents $n$ for PBSU at various blend compositions

Crystallization temperature of PBSU was $90^{\circ} \mathrm{C}$.

\begin{tabular}{cc}
\hline PBSU/PVDF & Avrami exponent, $n$ \\
\hline $100: 0$ & 2.2 \\
$80: 20$ & 1.9 \\
$60: 40$ & 1.6 \\
$40: 60$ & 1.5 \\
$40: 60^{\mathrm{a}}$ & $1.4,1.0$ \\
\hline
\end{tabular}

a Two-step crystallization was used in crystallizing PBSU (see Figure 1 (d) or explanation in the text).

tions of PVDF in Figure 10. In general, the Avrami exponents of crystalline component in amorphous/ crystalline blend remain constant or increase with amorphous composition. ${ }^{7,41}$ However, as shown in Table XI, the Avrami exponents of PBSU decreased with PVDF composition. Since the nucleation mechanism of PBSU was unchanged by blending PVDF (see Figure 12), the decrease in the Avrami exponent of PBSU may be accounted for by the changes in the geometry of growing PBSU crystals. Actually, PBSU in the blend should crystallize in the matrix of PVDF crystals, whereas pure PBSU crystallizes in the melt of PBSU itself. Although it is impossible to discuss the geometry of growing PBSU crystals in the blend and in the pure state quantitatively, it is certain that the PVDF crystals act as obstacle at the growth front of PBSU crystals which reduce the dimension of the PBSU crystal growth. Similar discussions were made by Manley et $a l .^{11}$ in PBA/PVDF system.

A unique result was obtained for the Avrami plot of PBSU/PVDF $(40: 60)$ blend. The slope of the fitted line in Figure 16 was straight for the PBSU crystallized directly at $90^{\circ} \mathrm{C}$ (symbol $\triangle$ in Figure 16), whereas the 


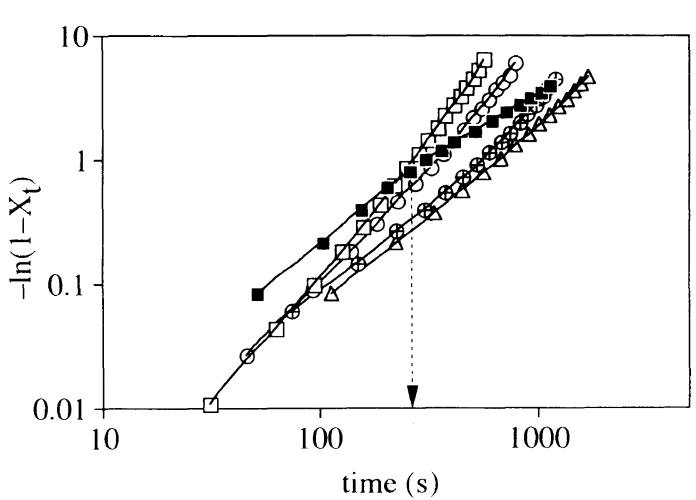

Figure 16. Avrami plots for PBSU at various blend compositions. $\square$, PBSU $100 \%$; $\bigcirc$, PBSU $80 \%$; $\oplus$, PBSU $60 \% ; \triangle$, PBSU $40 \%$; PBSU $40 \%$. All the samples were cooled directly from the melt to $90^{\circ} \mathrm{C}$ and isothermally crystallized at this temperature after maintaining at $190^{\circ} \mathrm{C}$ for $5 \mathrm{~min}$, except for the sample $\square$. The sample $\square$ (PBSU 40\%) was crystallized with two-steps described in the text.

slope of the PBSU crystallized with two steps (symbol $\square$ in Figure 16, see the explanation of Figure 14) has two slopes which changed at the crystallization time was ca. $5 \mathrm{~min}$. This finding is supported by the microscopic observation of the crystallization of PBSU crystals in the PVDF spherulites (Figure 14); the PBSU in the interspherulitic regions crystallize instantly within $5 \mathrm{~min}$, whereas the PBSU in the interlamellar region of PVDF crystallizes slowly and takes long time.

Finally, we showed that the crystal morphology of the low $-T_{\mathrm{m}}$ component PBSU changed dramatically with the crystallization conditions of high- $T_{\mathrm{m}}$ component PVDF (for example, compare Figures 12(d) and 14(d)). These morphological changes observed in crystalline/crystalline blends could have significant meaning with regard to the mechanical properties of blends.

Acknowledgments. The authors would like to thank Mr. T. Morioka and his research group in TOUNEN CHEMICAL CORP. for synthesizing the biodegradable polyester PBSU and their helpful discussions.

\section{REFERENCES}

1. T. Nishi and T. T. Wang, Macromolecules, 8, 909 (1975).

2. C. J. Ong and F. P. Price, J. Polym. Sci., Polym. Symp., 63, 45 (1978).

3. C. J. Ong and F. P. Price, J. Polym. Sci., Polym. Symp., 63, 59 (1978).

4. S. Nojima, K. Watanabe, Z. Zheng, and T. Ashida, Polym. J., 20, 823 (1988).

5. R. S. Barnum, J. W. Barlow, and D. R. Paul, J. Appl. Polym. Sci., 27, 4065 (1982).

6. E. G. Lezcano, C. Salom Coll, and M. G. Prolongo, Polymer, 37, 3603 (1996).

7. E. D. Paglia, P. L. Beltrame, M. Canetti, A. Seves, B. Marcandalli, and E. Martuscelli, Polymer, 34, 996 (1993).
8. P. Greco and E. Martuscelli, Polymer, 30, 1475 (1989).

9. J. C. Lee, K. Nakajima, T. Ikehara, and T. Nishi, J. Polym. Sci, Part B, Polym. Phys., accepted

10. J. P. Penning and R. St. John Manley, Macromolecules, 29, 77 (1996).

11. J. P. Penning and R. St. John Manley, Macromolecules, 29, 84 (1996).

12. K. Fujita and T. Kyu, Macromolecules, 29, 91 (1996).

13. J. C. Wittmann and R. St. John Manley., J. Polym. Sci., Part B, Polym. Phys., 15, 1089 (1977).

14. C. K. Sham, G. Guerra, F. E. Karase, and W. J. Mackinght, Polymer, 29, 1016 (1988).

15. G. D. Wignall, J. D. Londono, J. S. Lin, R. G. Alamo, M. J. Galante, and L. Mandelkern, Macromolecules, 28, 3156 (1995).

16. K. P. Gallagher, X. Zhang, J. P. Runt, G. Huynh-ba, and J. S. Lin, Macromolecules, 26, 588 (1993).

17. J. Runt, L. Lin, S. Talibuddin, and C. R. Davis, Macromolecules, 28, 2781 (1995).

18. H. Tanaka and A. J. Lovinger, J. Polym. Sci., Part B, Polym. Phys., 28, 2183 (1990).

19. J. W. Cho, S. Tasaka, and S. Miyata, Polym. J., 25, 1267 (1993).

20. M. Aubin, Y. Bedard, M. F. Morrissette, and R. E. Prud'homme, J. Polym. Sci., Part B, Polym. Phys., 21, 233 (1983).

21. H. Zhang and R. E., Prud'homme, J. Polym. Sci., Part B, Polym. Phys., 24, 723 (1987).

22. M. Avella and E. Martuscelli, Polymer, 29, 1731 (1988).

23. R. Pearce and R. H. Marchessault, Polymer, 35, 3990 (1994).

24. S. J. Organ and P. J. Braham, Polymer, 34, 2169 (1993).

25. D. C. Wahrmund, R. E. Bernstein, J. W Barlow, and D. R. Paul, Polym. Eng. Sci., 18, 677 (1978).

26. R. E. Bernstein, D. R. Paul, and J. W. Barlow, Polym. Eng. Sci., 18, 683 (1978).

27. J. D. Hoffman and J. J. Weeks, J. Res. Natl. Bur. Stand., 66, 13 (1962).

28. P. J. Flory, in "Principles of Polymer Chemistry," Cornell Univ., New York, N.Y., 1953.

29. D. W. Van Krevelan, in" Properties of Polymers," Elsevier Scientific Publishing, New York, N.Y., 1976.

30. E. Blumm and A. J. Owen, Polymer, 36, 4077 (1995).

31. H. D. Keith, F. J. Padden, Jr., and T. P. Russel, Macromolecules, 22, 666 (1989).

32. Y. Urai, T. Ikehara, and T. Nishi, Trans. Mater. Res. Soc. Jpn., 15A, 221 (1994).

33. J. C. Lee, K. Nakajima, T. Ikehara, and T. Nishi, J. Appl. Polym. Sci., 64, 797 (1997).

34. D. K. Song and Y. K. Sung, J. Appl. Polym. Sci., 56, 1381 (1995).

35. K. S. Ihn, E. S. Yoo, and S. S. Im, Macromolecules, 28, 2460 (1995).

36. P. J. Braham, A. Keller, E. L. Otun, and P. A. Holmes, J. Mater. Sci., 26, 1368 (1991).

37. S. J. Organ and P. J. Braham, J. Mater. Sci., 19, 2781 (1984).

38. M. M. Coleman and J. Zarian, J. Polym. Sci., Part B, Polym. Phys., 17, 837 (1979).

39. D. F. Varnell, J. P. Runt, and M. M. Coleman, Polymer, 24, 37 (1983).

40. M. Avrami, J. Chem. Phys., 7, 1103 (1939).

41. E. Martuscelli, M. Parcella and W. P. Yue, Polymer, 25, 1097 (1984).

42. H. H. Song, R. S. Stein, D. Q. Wu, M. Ree, J. C. Phillips, A. LeGrand, and B. Chu, Macromolecules, 21, 1180 (1988).

43. R. S. Stein, J. Cronauer, and H. G. Zachmann, J. Molec. Struct., 383, 19 (1996).

44. K. Tashiro, Acta Polymerica, 46, 100 (1995). 